\title{
Liposomal Mitoxantrone Hydrochloride
}

National Cancer Institute

\section{Source}

National Cancer Institute. Liposomal Mitoxantrone Hydrochloride. NCI Thesaurus. Code C116064.

A formulation composed of the hydrochloride salt form of the anthracenedione antibiotic mitoxantrone encapsulated within liposomes, with potential antineoplastic activity. Upon intravenous administration, mitoxantrone intercalates into and forms crosslinks with DNA, thereby disrupting DNA and RNA replication. This agent also binds to topoisomerase II, which both results in DNA strand breaks and prevents DNA synthesis. This leads to the induction of apoptosis in the rapidly dividing cancer cells. The liposomal delivery of mitoxantrone improves drug penetration into tumors and decreases drug clearance, thereby increasing drug circulation and therapeutic efficacy while lowering the toxic effects. 